\title{
Iranian stroke patient's perception of dignity, autonomy and privacy: a questionnaire survey
}

\author{
Behnam Sadeghzadeh $^{1}$, Ghasem Fattahzadeh-Ardalani ${ }^{2}$, Azad Rahmani ${ }^{1}$, \\ Vahid Zamanzadeh $^{1}$, Mojgan Behshid ${ }^{1}$, Arman Azadi ${ }^{3}$
}

\footnotetext{
${ }^{1}$ Nursing and Midwifery Faculty, Tabriz University of Medical Sciences, Tabriz, Iran

${ }^{2}$ Ardabil University of Medical Sciences, Iran

${ }^{3}$ Ilam University of Medical Sciences, Iran
}

Received: 18 July 2016

Accepted: 10 August 2016

\author{
*Correspondence: \\ Dr. Ghasem Fattahzadeh-Ardalani \\ E-mail: g.fattahzadeh2015@gmail.com
}

Copyright: () the author(s), publisher and licensee Medip Academy. This is an open-access article distributed under the terms of the Creative Commons Attribution Non-Commercial License, which permits unrestricted non-commercial use, distribution, and reproduction in any medium, provided the original work is properly cited.

\begin{abstract}
Background: Patients with stroke have many problems which may have adverse effects on opportunities for dignified care. So, any plans to improve the providing of dignified care in these patients need to identify the level of maintaining their dignity in hospital settings and its related factors in particular privacy and autonomy. Accordingly, the aim of this study was to recognize the level of self-perceived dignity and its relationships with the perception of respected autonomy and privacy among Iranian stroke patients.

Methods: This descriptive-correlational study was undertaken among 166 patients with stroke admitted to a public educational centre affiliated to Ardebil University of Medical Sciences, Ardebil/Iran. They were selected using convenience sampling method. Patients' levels of self-perceived dignity, autonomy and privacy were assessed using valid questionnaires.

Results: The study findings showed a significant negative correlation between patients' self-perceived dignity and autonomy. Also there was no significant relationship between patients' self-perceived dignity and patients' perception of protected privacy.

Conclusions: According to the findings of this study respect to autonomy of patient increases the amount of patient dignity. But there isn't this relationship about respect to the privacy of patient.
\end{abstract}

Keywords: Dignity, Autonomy, Privacy, Stroke

\section{INTRODUCTION}

The increasing prevalence of chronic diseases and the need for long-term care can have an impact on the patients and their families' lives. ${ }^{1,2}$ Stroke is one of the main causes of death and disability which affect patients independence in activities of daily living. ${ }^{3,4}$ The findings of studies in Germany and Japan have shown that one out of five of the general population have at least one stroke event in their lives. ${ }^{5,6}$ Some studies in Iran reported higher prevalence of stroke events among Iranian population compared to developed countries. ${ }^{7,8}$
Stroke patients' experience many physical and psychosocial problems. Most of activities of daily living of stroke patients are performed by related agencies or family members which may adversely affect patient's autonomy. ${ }^{1-9}$ So, respecting these patients' human rights and dignity is crucial. ${ }^{10}$ Dignity is a core concept in nursing care of stroke patients and respecting their dignity is critical to their recovery. ${ }^{11}$

Oxford dictionary defines dignity as "the state or quality of being worthy of honour or respect". In the case of patients it means honourable or respectful treatment or 
care. $^{12}$ There are few studies which have examined dignity among stroke patients. The findings of FletcherSmith et al study in the UK showed that the dignity of stroke patients was not maintained well. ${ }^{13}$ As well, there no studies examining Iranian stroke patients' perception of their dignity in the hospital setting. However, the findings of some qualitative studies showed that Iranian patients believed that their dignity is not respected in hospital settings. ${ }^{14-16}$

The dignity is an abstract and complicated concept which influenced by many factors. So, identifying factors associated with this concept is required for providing dignified care. ${ }^{17}$ Respecting patients' privacy and autonomy, keep patients' secrets confidential, listen to and honour patients, allowing patients to speak about their concerns and have the right to choose/refuse treatment has been mentioned in previous studies as important factors that are likely to influence patients dignity. ${ }^{11}$ Protecting patients' privacy and respecting their autonomy are two important concepts that are related to dignity. ${ }^{18-23}$ However these relationships are not well investigated in previous studies. ${ }^{18}$

For many reason patients with stroke are more susceptible to loss of dignified care. ${ }^{9}$ To the best of our knowledge, there are inadequate studies that examined patients' perception of dignified care and its association with privacy and autonomy. Accordingly, the aim of this study was to recognize the level of self-perceived dignity and its relationships with the perception of respected autonomy and privacy among Iranian stroke patients.

\section{METHODS}

This descriptive-correlational study was conducted in an educational centre affiliated to Ardebil University of Medical Sciences, Ardebil, Iran. This centre has one hospitalization ward and two out-patient clinics for stroke patients.

The study population included all patients who referred to the educational centre during the study period and met the following criteria: (a) be at least 18 years old; (b) having confirmed stroke diagnosis; (c) having paresis or plegia in at least one limb; (d) transition from the acute to the rehabilitative phase; (e) no dependency to others for activities of daily living; (f) absence of aphasia; and (g) willing to participate and answer to questions. Patients with any other chronic diseases or severe psychological disorder were excluded. The sample size $(n=150)$ was calculated based on a pilot study of 30 patients. A convenience sample of 310 stroke patients was assessed. Overall, 172 stroke patients met the criteria; of those 166 patients accepted to be enrolled (response rate=97\%).

The instrument for data collection composed of four parts. The first part composed of some items to collect the demographic/disease-related characteristics of patients which collected according to patients self-report or their medical records. The second part was Vlug scale developed by Vlug et al. ${ }^{17}$ This scale has 26 items classified according to a five-point Likert scale ranging from 1 (never) to 5 (Very Frequently). The total score of this scale is 26 to 130 points; the higher the score indicate higher respected dignity. ${ }^{17}$ The third part was Bout scale developed by Bout et al. ${ }^{24}$ This scale has 22 items classified according to a five-point Likert scale ranging from 1 (strongly agree) to 5 (strongly disagree). The total score of this scale is 22 to 110 points; the higher the score indicate lower respected autonomy. ${ }^{24}$ The forth part was a scale developed by Arciero et al in 1993. ${ }^{25}$ This scale has 13 items classified according to a four-point Likert scale ranging from 1 (never respected) to 4 (always respected). The total score of this scale is 13 to 52 points; the higher the score indicate higher respected privacy. ${ }^{25}$

For using the questionnaires, the scales were translated into Persian and then, the accuracy and fluency confirmed by a translator expert in both Persian and English languages. The scales face and content validity were assessed and verified by the expert panel constituted ten members. The final version of the questionnaires was tested for reliability in a pilot study involving 30 stroke patients. Cronbach-alpha coefficient values for all scales were higher than 0.89 .

Before the data collection, the study proposal was approved by the regional ethics committee of Tabriz University of Medical Sciences. Next, researchers were referring to the hospitalization ward and both out-patient clinics from April to July 2015. Patients who met criteria for the study were identified and all eligible patients were invited to participate. After being presented basic information, willing patients were asked to participate in a private interview for data collection. All patients who participated in the study gave informed consent.

Data were analysed using SPSS version 13. Descriptive statistics such as the mean and standard deviation were used to describe demographic/disease-related data. Relationships between patients' perception of dignity with levels of respected autonomy and privacy were assessed by Pearson's correlation.

\section{RESULTS}

Table 1 shows some socio-demographic and diseaserelated characteristics of the patients. As shown in Table 1 , most of participants were male, married, illiterate, housewife, more than $78 \%$ of patients over 60 years old, lived with their spouse and children and had a financial condition of income less than cost. Also, most of them were hospitalized more than 10 days and their physical problems were often accompanied by hemiparesis.

The mean of patients scores in three questionnaires of dignity, autonomy and privacy is represented in Table 2. As shown in Table 2, patients' dignity and privacy was moderately maintained according to patients' responses. However, maintenance of patients' autonomy was higher than dignity and privacy. 
Table 1: Participant demographic and disease-related characteristics.

\begin{tabular}{|c|c|c|c|}
\hline Variable & Sub-groups & Number & Percent \\
\hline \multirow{2}{*}{ Gender } & Male & 97 & 58.4 \\
\hline & Female & 69 & 41.6 \\
\hline \multirow{3}{*}{ Education } & Illiterate & 101 & 60.8 \\
\hline & $\begin{array}{l}\text { Diploma and } \\
\text { lower }\end{array}$ & 63 & 38 \\
\hline & $\begin{array}{l}\text { University } \\
\text { degree }\end{array}$ & 2 & 1.2 \\
\hline \multirow{3}{*}{ Marital status } & Married & 161 & 97 \\
\hline & Single & 3 & 1.8 \\
\hline & $\begin{array}{l}\text { Divorced } \backslash \\
\text { Widow }\end{array}$ & 2 & 1.2 \\
\hline \multirow{3}{*}{$\begin{array}{l}\text { Economic } \\
\text { status }\end{array}$} & $\begin{array}{l}\text { Income equal } \\
\text { to cost }\end{array}$ & 63 & 38 \\
\hline & $\begin{array}{l}\text { Income more } \\
\text { than cost }\end{array}$ & 6 & 3.6 \\
\hline & $\begin{array}{l}\text { Income less } \\
\text { than cost }\end{array}$ & 97 & 58.4 \\
\hline \multirow{2}{*}{ Settlement } & Town /city & 117 & 70.5 \\
\hline & Village & 49 & 29.5 \\
\hline \multirow{4}{*}{$\begin{array}{l}\text { Living } \\
\text { situation }\end{array}$} & Alone & 3 & 1.8 \\
\hline & With parents & 1 & 0.6 \\
\hline & With spouse & 35 & 21.1 \\
\hline & $\begin{array}{l}\text { With spouse } \\
\text { and children }\end{array}$ & 127 & 76.5 \\
\hline \multirow{2}{*}{$\begin{array}{l}\text { Time of } \\
\text { hospitalization }\end{array}$} & $\begin{array}{l}\text { Less than } 10 \\
\text { days }\end{array}$ & 82 & 49.4 \\
\hline & $\begin{array}{l}\text { More than } 10 \\
\text { days }\end{array}$ & 84 & 50.6 \\
\hline \multirow{3}{*}{$\begin{array}{l}\text { Physical } \\
\text { problem } \\
\text { caused by the } \\
\text { disease }\end{array}$} & Hemiplegia & 19 & 11.4 \\
\hline & Paraplegia & 24 & 14.5 \\
\hline & Hemiparesis & 123 & 74.1 \\
\hline
\end{tabular}

Table 2: The scores of participants in study questionnaires (based on 100).

\begin{tabular}{|lll|}
\hline Variables & Mean & SD \\
\hline Total dignity score & 70.04 & 13.83 \\
\hline $\begin{array}{l}\text { Evaluation of self in relation } \\
\text { to others }\end{array}$ & 72.19 & 16.68 \\
\hline Functional status & 70.66 & 13.70 \\
\hline Mental state & 72.08 & 18.04 \\
\hline Care and situational aspects & 63.83 & 21.78 \\
\hline Total autonomy score & 42.45 & 8.50 \\
\hline Total privacy score & 71.38 & 13.63 \\
\hline
\end{tabular}

There was a significant negative correlation between patients' self-perceived dignity and their perception regarding maintenance of their autonomy $(r=-0.27 ; p=$ 0.001). Similarly, there was not a significant relationship between patients' self-perceived dignity and their perception regarding protecting of privacy $(\mathrm{r}=0 / 098 ; \mathrm{p}=$ $0.001)$.

\section{DISCUSSION}

The aim of this study was to evaluate the level of selfperceived dignity and its relationships with the perception of respected autonomy and privacy among Iranian stroke patients.

The study findings showed that the dignity of Iranian stroke patients was preserved moderately. According to extensive literature review there are few studies which explore stroke patients' perception of dignity. ${ }^{26}$ However several studies were assessed the overall state of maintenance of patients' dignity in clinical settings. For example, Avestan et al reported that the dignity of Iranian cancer patients is not properly maintained in clinical settings. ${ }^{27}$

The findings of Birrell et al in UK also showed that many patients were not satisfied with the maintenance of their dignity in clinical settings. ${ }^{26}$ In another study in England Fletcher-Smith et al reported similar findings. ${ }^{13}$ The findings of a qualitative study by Torabizadeh et al showed that the dignity of Iranian patients is not preserved in hospital settings. ${ }^{15}$ It seems workforce shortage and some shortcoming of educational hospitals such as presence of medical students during patient visits, lack of hospital bed and high number of patients in hospital rooms are most reasons indicating that the dignity of Iranian patients is not properly maintained in hospital settings.

The study findings also showed that the privacy of study participants was maintained moderately. Contrary to our findings Woogara et al in England reported that the patients' privacy is not protected in hospital settings. ${ }^{28}$ Karro et al in Australia also reported similar findings. ${ }^{29}$ However the findings of studies in United States and Turkey showed patients satisfaction of having their privacy respected. ${ }^{30,31}$ The findings of some studies in Iran also revealed that patients' privacy is not protected appropriately. ${ }^{15,16}$ It appears that some factors such as the large number of patients in hospital rooms and overcrowded healthcare settings are important causes of unmet patients' expectations of privacy.

As another finding of this study, patients believed that maintenance of autonomy was higher than dignity and privacy. Some studies reported a lack of regard for patients' autonomy in Europeans countries. ${ }^{32,33}$ Xiong et al also reported that Chinese patients' autonomy is not respected in hospital setting. ${ }^{4}$ Rahmani et al also reported that the privacy of Iranian patients is not completely protected in clinical settings. ${ }^{34}$ The findings of Ebrahimi et al study in Iran revealed that respect to patients' autonomy can be result in patients' physical/mental comfort, independence, adherence to treatment and selfconfidence. ${ }^{35}$ However, the combination of sensory and motor deficits in stroke patients may adversely affect 
their sense of not maintained autonomy. For example, Akbari et al reported that there was correlation between upper extremity function and independence in activates of daily living among stroke patients. ${ }^{36}$

The study finding also showed a significant negative correlation between patients' self-perceived dignity and their perception regarding maintenance of the autonomy.

Despite the strength of this study, it also has some limitations. First, a sample of patients admitted to a medical center in East Azerbaijan province in northwestern of Iran cannot represent the overall state of perceived dignity among Iranian stroke patients. Next, the data were obtained using interview which may limit the implication of our study. In relation to future research, investigating other factors that may affect the dignity of stroke patients require further investigation. Exploring family and healthcare workers' perception of dignity is also recommended.

\section{ACKNOWLEDGEMENTS}

This is a report of a database from a thesis approved by Tabriz University of Medical Sciences. The authors wish to acknowledge all of the patients, whose contribution enabled the production of this article.

\section{Funding: No funding sources}

Conflict of interest: None declared

Ethical approval: The study was approved by the institutional ethics committee

\section{REFERENCES}

1. Organization WH. WHO STEPS Stroke Manual: The WHO STEP wise approach to stroke surveillance. 2005.

2. Brunner LS, Smeltzer SCC, Bare BG, Hinkle JL, Cheever KH. In: Brunner \& Suddarth's textbook of medical-surgical nursing. Lippincott Williams \& Wilkins; 2010.

3. Hankey GJ. Preventable stroke and stroke prevention. Journal of thrombosis and haemostasis. JTH. 2005;3(8):1638-45.

4. Xiong L, Leung H, Chen XY, Han JH, Leung T, Soo $\mathrm{Y}$, et al. Preliminary findings of the effects of autonomic dysfunction on functional outcome after acute ischemic stroke. Clinical neurology and neurosurgery. 2012;114(4):316-20.

5. Seshadri S, Beiser A, Kelly-Hayes M, Kase CS, Au $\mathrm{R}$, Kannel WB, et al. The lifetime risk of stroke: estimates from the Framingham Study. Stroke a journal of cerebral circulation. 2006;37(2):345-50.

6. Turin TC, Kokubo Y, Murakami Y, Higashiyama A, Rumana N, Watanabe $M$, et al. Lifetime risk of stroke in Japan. Stroke a journal of cerebral circulation. 2010;41(7):1552-4.

7. Borhani-Haghighi A, Safari R, Heydari ST, Soleimani F, Sharifian M, Yektaparast Kashkuli S, et al. Hospital mortality associated with stroke in southern iran. Iranian journal of medical sciences. 2013;38(4):314-20.

8. Azarpazhooh MR, Etemadi MM, Donnan GA, Mokhber N, Majdi MR, Ghayour-Mobarhan M, et al. Excessive incidence of stroke in Iran: evidence from the Mashhad Stroke Incidence Study (MSIS), a population-based study of stroke in the Middle East. Stroke a journal of cerebral circulation. 2010;41(1):3-10.

9. Stinear C. Prediction of recovery of motor function after stroke. The Lancet Neurology. 2010;9(12):1228-32.

10. Lewkonia R. Patient rights and medical education: clinical principles. Medical teacher. 2011;33(5):3926.

11. Matiti MR, Trorey G. Perceptual adjustment levels: patients' perception of their dignity in the hospital setting. International journal of nursing studies. 2004;41(7):735-44.

12. Stevenson A. Oxford dictionary of English. Oxford University Press; 2010.

13. Fletcher-Smith J, Walker MF, Drummond A. The influence of hand use on dressing outcome in cognitively impaired stroke survivors. The British Journal of Occupational Therapy. 2012;75(1):2-9

14. Nayeri ND, Aghajani M. Patients' privacy and satisfaction in the emergency department: a descriptive analytical study. Nursing ethics. 2010;17(2):167-77.

15. Torabizadeh C, Ebrahimi H, Mohamadi E. The Relationship between Patients' Privacy and Dignity. Medical Ethics. 2012;1(19):121-33.

16. Ebrahimi H, Torabizadeh C, Mohammadi E, Valizadeh S. Patients' perception of dignity in Iranian healthcare settings: a qualitative content analysis. Journal of medical ethics. 2012;38(12):723-8.

17. Vlug MG, De-Vet HC, Pasman HR, Rurup ML, Onwuteaka-Philipsen BD. The development of an instrument to measure factors that influence selfperceived dignity. Journal of palliative medicine. 2011;14(5):578-86.

18. Cairns D, Williams V, Victor C, Richards S, Le May A, Martin W, et al. The meaning and importance of dignified care: findings from a survey of health and social care professionals. BMC geriatrics. 2013;13:28.

19. Whitehead J, Wheeler H. Patients' experience of privacy and dignity. Part 2: An empirical study. British journal of nursing. 2008;17(7):458-64.

20. Delmar C, Alenius-Karlsson N, Mikkelsen AH. The implications of autonomy: Viewed in the light of efforts to uphold patients dignity and integrity. International journal of qualitative studies on health and well-being. 2011;6(2):6045.

21. Delmar C, Boje T, Dylmer D, Forup L, Jakobsen C, Moller M, Sonder H. Independence/dependence--a contradictory relationship? Life with a chronic 
illness. Scandinavian journal of caring sciences. 2006;20(3):261-8.

22. Kozier B. Fundamentals of nursing, concepts, process and practice. Pearson Education; 2008.

23. Chaichana KL, Halthore AN, Parker SL, Olivi A, Weingart JD, Brem $\mathrm{H}$, et al. Factors involved in maintaining prolonged functional independence following supratentorial glioblastoma resection. Clinical article. Journal of neurosurgery. 2011;114(3):604-12.

24. Stiggelbout AM, Molewijk AC, Otten W, Timmermans DR, van Bockel JH, Kievit J. Ideals of patient autonomy in clinical decision making: a study on the developmentof a scale to assess patients' and physicians' views. Journal of medical ethics. 2004;30(3):268-74.

25. Back E, Wikblad K. Privacy in hospital. Journal of advanced nursing. 1998;27(5):940-5.

26. Birrell J, Thomas D, Jones CA. Promoting privacy and dignity for older patients in hospital. Nursing standard. 2006;20(18):41-6.

27. Avestan Z, Rahmani A, Heshmati-Nabavi F, Mogadasian S, Faghani S, Azadi A, et al. Perceptions of Iranian Cancer Patients Regarding Respecting their Dignity in Hospital Settings. Asian Pacificjournal of cancer prevention. APJCP. 2015;16(13):5453-8.

28. Woogara J. Patients' privacy of the person and human rights. Nursing ethics. 2005;12(3):273-87.

29. Karro J, Dent AW, Farish S. Patient perceptions of privacy infringements in an emergency department. Emergency medicine Australasia. EMA. 2005;17(2):117-23.

30. Barlas D, Sama AE, Ward MF, Lesser ML. Comparison of the auditory and visual privacy of emergency department treatment areas with curtains versus those with solid walls. Annals of emergency medicine. 2001;38(2):135-9.

31. Akyuz E, Erdemir F. Surgical patients' and nurses' opinions and expectations about privacy in care. Nursing ethics. 2013;20(6):660-71.

32. Suhonen R, Valimaki M, Dassen T, Gasull M, Lemonidou C, Scott PA, et al. Patients' autonomy in surgical care: a comparison of nurses' perceptions in five European countries. International nursing review. 2003;50(2):85-94.

33. Moser A, Houtepen R, Widdershoven G. Patient autonomy in nurse-led shared care: a review of theoretical and empirical literature. Journal of advanced nursing. 2007;57(4):357-65.

34. Rahmani A, Ghahramanian A, Alahbakhshian A. Respecting to patients' autonomy in viewpoint of nurses and patients in medical-surgical wards. Iranian journal of nursing and midwifery research. 2010;15(1):14-9.

35. Ebrahimi H, Sadeghian E, Seyedfatemi N, Mohammadi E. Challenges associated with patient autonomy in Iranian hospitals: a qualitative study. Iranian Journal of Medical Ethics and History of Medicine. 2014;7(4):92-103.

36. Akbari S, AshayeriH, Fahimi MA, Kamali M, Lyden PD. The correlation of independency in activities of daily living performance with cognitive status and the intensity of neurological impairment in right-handed stroke patients. Neuro Rehabilitation. 2010;29(3):311-6.

Cite this article as: Sadeghzadeh B, FattahzadehArdalani G, Rahmani A, Zamanzadeh V, Behshid M, Azadi A. Iranian stroke patients perception of dignity, autonomy and privacy: a questionnaire survey. Int J Sci Rep 2016;2(9):237-41. 